\title{
Book Review of Documenta 12 Education Volumes 1 and 2
}

\author{
W. Wieczorek, C. Hummel, U. Schötker, A. Güleç and S. Parzefall, Editors, Documenta 12 \\ Education, Volume 1: Engaging Audiences, Opening Institutions: Methods and Strategies in Gallery \\ Education at Documenta 12, Diaphanes Verlag, Zurich (2009), 213 pages, $f 19.98$ (paperback with \\ DVD, ISBN 978-3-03734-081-3).
}

and

C. Mörsch and the Research Team of the Documenta 12 Education, Editors, Documenta 12 Education, Volume 2: Between Critical Practice and Visitor Services: Results of a Research Project, Diaphanes Verlag, Zurich (2009), 376 pages, £15.63 (paperback, ISBN 978-3-03734-082-0).

\section{Emese Hall}

These two books about gallery education are designed to complement each other. I suggest that Volume 1 can be read independently of Volume 2, but Volume 2 would not be entirely coherent without having first read Volume 1. I will comment on each volume separately, but I begin with a brief summary of my thoughts on the books as a pair.

Documenta is a contemporary art exhibition held in the German town of Kassell every five years for 100 days. The first exhibition was held in 1955 and documenta 12 was held in 2007, with a particular emphasis on education. One criticism is that it seems to be assumed that the reader is already familiar with documenta. I argue that more detail should have been provided about the history and aims of the exhibition in the introduction to Volume 1. My main criticism is that although links to other chapters and the DVD are highlighted throughout both volumes, much of what is written only becomes comprehensible when it is contexualised by information given elsewhere, often in fragments. (The links do not offer any assistance in this respect.) For example, it is not until over halfway through Volume 1 that the scale of documenta 12 is detailed: five buildings, 122 artists, and approximately 500 artworks. As a final general observation, the books would have been easier to navigate with some numerical signposting in the form of section and chapter numbers, and indexes might also have usefully been included.

Volume 1 is described as giving: 'a comprehensive and richly illustrated survey of formats and models of education and collaboration with the public at documenta 12. The accompanying DVD complements the publication by virtue of firsthand material documenting the practice of gallery education at document 12. Additional texts allow one to delve deeper into the subject, as well as to browse through heretofore unpublished image and video material.' 
With its many images and short chapters, this book gives the initial impression that parts of it can be read separately. However, related to my concerns about ambiguity stated above, I found that it was essential to read the book thoroughly from the beginning. Despite these shortcomings, the book features various examples of innovative and creative approaches to gallery education that could provide inspiration for those with an interest in this area.

Knowledge transfer, cooperation, sharing, and collaboration were key features of documenta 12. The section on 'Activities of the documenta 12 advisory board' is presented clearly in the form of project outlines that shows the impressive range of educational activities that were offered to diverse groups. For example, the 'Inhabiting the World' project involved small teams of teenagers collaborating to explore the educational potential of the exhibition in order to design and conduct their own tours. The essays in the section devoted to 'Inhabiting the world', some of which were written by the young people, gave insight into the value of the project. For example, Haselroth's reflection on the challenges of conducting a tour for blind people raised some pertinent considerations about gallery education for those with disabilities. Many of the projects mentioned in the book discuss how art can be explored physically, such as 'Taking over space'. Neuman reflects on this project, led by artist Annette Krauss, where groups of children were invited to find their own routes around the exhibition and record these journeys by video and photographs in order to share them with other children. This approach was described as 'perfomative'; a key word in the documenta 12 vocabulary.

The DVD could have been an engaging addition to the text, but I found it to be unremarkable. It is unfortunate that the DVD is in German as this limits its accessibility. However, even without an understanding of the German language one might expect to be able to benefit from the audiovisual material. There were coloured images and some sound, but the video content was elusive. References to the DVD are made in both volumes, so obvious thought has gone into how the DVD material relates to the text, but I was uncertain of its exact value.

Volume 2 is described as focusing on: 'a theory of gallery education, its methods and contexts, and reflects theoretically on examples presented in Volume 1. It is addressed to professionals from the field of gallery education, cultural education and formal education.'

The 27 chapters, or 'articles', in this book address assorted themes, including: racism, sexism, sexuality, power structures, performance, communication, aesthetics, and postcolonialism. The clarity of the articles is variable, but they are nonetheless worthy of attention as these social and political issues are of global relevance to both art and art education. For example, Mörsch provides 
a critical discussion about traditions and contemporary trends in gallery education, identifying four discourses: affirmative, reproductive, deconstructive, and transformative. She explains that research into gallery education was a special feature of documenta 12 and 21 gallery educators participated in an action research project. The findings are presented in the articles, but the precise details of the research are not given and therefore it is not possible to determine the validity or rigour of the investigations.

A highlight in this volume is Sato's essay on 'Performing essentialism at documenta 12', where he describes his perceptions as a non-German gallery educator, with Japanese/Peruvian heritage and Austrian citizenship. Issues around identity and prejudice are considered both in terms of the visitors' perceptions of Sato and their interest in and interpretation of the artworks, which varied considerably depending on how he presented himself to the public. Importantly, he argues that gallery education is never neutral and this is one of the main messages of the book. Another article that I found interesting was Distelberger's discussion about the role of the 'expert' in gallery education, which made thoughtful use of excerpts from conversations that took place during her time as a tour guide. Quotations from visitors, and observations, were also used effectively by other authors in examining various attitudes and behaviours.

The glossary covers both general terms (e.g., 'discourse') and terms specific to documenta 12 (e.g., 'palm groves'), which do require elucidation. Descriptions of selected artworks are also included, although it would have been interesting to see coloured photographs of these on the DVD. There are high quality black and white images in both books, but I do not think these can do full justice to the artworks. Obviously, this is one of the limitations of trying to describe a large art exhibition in book-format.

In conclusion, the topic of 'gallery education' is critically examined from a range of angles in both of these volumes and there are numerous ideas that can be explored in other contexts, theoretically and practically. The range of perspectives given is commendable, demonstrating the inclusive nature of the exhibition and its education programme. It is notable that the documenta education projects involved adults as well as children and young people, so the books should appeal to a wide audience. However, in actuality I think that the readership may be limited to those who are prepared to persevere with the issues regarding comprehensibility noted above. 